\title{
EKSPLORASI PEMBELAJARAN MATEMATIKA SECARA DARING DALAM DIMENSI PEDAGOGIK
}

\author{
Yeni Yuniarti, Tita Mulyati, Yunus Abidin, Yusuf Tri Herlambang, Eri Yusron \\ Program Studi pendidikan Guru Sekolah Dasar Universitas Pendidikan Indonesia \\ Correspondene Email: yeni_yuniarti@upi.edu, yusufth@upi.edu
}

\begin{abstract}
Abstrak
Tujuan penelitian yaitu mengeksplorasi tantangan dan kesiapan guru dalam melaksanakan pembelajaran matematika secara daring dilihat dari dimensi-dimensi pedagogik dan melihat upaya guru dalam mengembangkan pembelajaran matematika secara daring. Penelitian ini menggunakan pendekatan kualitatif dengan metode studi eksplorasi. Teknik sampling yang digunakan yaitu purposive sampling. Subjek penelitian yaitu orang tua/wali siswa dan guru yang melaksanakan pembelajaran matematika secara daring. Pengumpulan data menggunakan kuesioner dan wawancara. Instrumen yang digunakan sudah divalidasi oleh ahli dan nilai validasi yaitu o,803 yang mengindikasikan sangat valid. Analisis data menggunakan statistik deskriptif dan analisis model Bogdan \& Biklen. Hasil temuan menunjukkan bahwa tantangan dalam pembelajaran matematika secara daring yaitu peningkatan literasi digital, fasilitas belajar, pengembangan karakter, dan evaluasi pembelajaran. Namun yang menjadi sorotan yaitu literasi digital. Hal ini menjadi faktor yang sangat penting dalam menjawab tantangan pada pembelajaran secara daring. Melihat hal tersebut, guru belum cukup siap dalam melaksanakan pembelajaran secara daring. Kemudian, upaya-upaya yang bisa dilakukan oleh guru dalam meningkatkan pembelajaran matematika berbasis daring yaitu pada segi pemahaman, guru perlu meningkatkan literasi teknologi, inovasi perencanaan pembelajaran dan perkembangan belajar. Sementara pada segi pelaksanaan guru perlu meningkatkan komunikasi, bimbingan, pendekatan menggunakan media teknologi dan kerjasama dengan orangtua pada proses pembelajaran.
\end{abstract}

\section{Kata Kunci: \\ Matematika, Daring, pedagogik}

\begin{abstract}
The research objective is to explore the challenges and readiness of teachers in implementing online mathematics learning from the pedagogical dimensions and seeing the efforts of teachers in developing online mathematics learning. This research uses a qualitative approach with an exploratory study method. The sampling technique used was purposive sampling. The research subjects were parents / guardians of students and teachers who carried out online mathematics learning. Data collection using questionnaires and interviews. The instrument used has been validated by experts and the validation value is 0.803 which indicates very valid. The data analysis used descriptive statistics and the Bogdan \& Biklen model analysis. The findings show that the challenges in learning mathematics online are increasing digital literacy, learning facilities, character development, and learning evaluation. But what is in the spotlight is digital literacy. This is a very important factor in responding to challenges in online learning. Seeing this, teachers are not quite ready to carry out online learning. Then, the efforts that can be made by teachers in improving online-based mathematics learning, namely in terms of understanding, teachers need to improve technological literacy, innovative learning planning and learning development. Meanwhile, in terms of implementation, teachers need to improve communication, guidance, approaches using technology media and collaboration with parents in the learning process.
\end{abstract}

Keywords:

Mathematics, Online, pedagogic

\section{A. Introduction}

Pada kondisi saat ini, potret perkembangan dunia sedang mengarah pada satu titik yang hampir seluruh aspek kehidupan manusia terpaut kepada hal krusial tersebut yang tak lain 
adalah digitalisasi. Realitas demikian terjadi selain karena imbas revolusi teknologi dan modernisasi, dewasa ini keadaan tersebut dipercepat dengan mewabahnya pandemi coronavirus yang dikenal umum dengan COVID-19 yang karenanya memaksa interaksi sosial secara tatap muka dan langsung menjadi terhambat. Terkait dengan itu, dapat dikatakan bahwa seluruh aspek kehidupan yang sebelumnya mengandalkan kontak fisik dalam polanya, kini mau tidak mau mesti merubah hampir seluruh aktivitasnya ke dunia digital (Astini, 2020). Berkenaan dengan semakin minimnya ruang kontak sosial secara langsung, dalam hal ini aspek pendidikan kemudian melakukan inovasi dengan lebih menggiatkan pembelajaran jarak jauh atau pembelajaran daring (Damanik et.al , 2020; Sa'pang \& Purbojo, 2020).

Adapun pembelajaran daring sendiri pada dasarnya mau tidak mau memang harus segera dilakukan dalam realitas perubahan zaman yang dipenuhi oleh berbagai macam perkembangan teknologi (Hidayat \& Prasetya, 2019). Pada dasarnya pembelajaran daring dilakukan selain demi menyesuaikan dan bentuk adaptasi terhadap kondisi dunia kekinian, lebih dari itu pembelajaran daring juga dimaksudkan demi membuat pola pendidikan yang lebih fleksibel, interaktif, dan efektif (Syamsuar \& Reflianto, 2019). Sejalan dengan hal tersebut Astini (2020) mengemukakan bahwa dengan dilaksanakannya pembelajaran daring maka diharapkan dapat membuat proses pembelajaran menjadi lebih baik. Berkaitan dengan di atas Damanik et.al (2020) berpendapat bahwa terdapat banyak cara untuk mengoptimalkan pembelajaran daring atau Online di antaranya adalah dengan menggunakan platform pembelajaran yang interaktif, mengemas materi secara lebih menarik, melakukan proses pemelajaran secara fleksibel dan luwes, serta penilaian di desain secara menarik.

Meskipun demikian, besar peluang menghasilkan pembelajaran yang efektif secara daring, namun realitas di lapangan masih banyak ditemukan kasus bahwa kesiapan dari faktor kunci pembelajaran itu sendiri yaitu guru masih jauh dari kondisi ideal mensukseskan pola pembelajaran daring (Khofiatun., Akbar, Sa'dun., dan Ramli, 2016). Masih terdapat guru yang secara kualifikasi masih belum memiliki kapasitas mumpuni dalam mengelola, mengimplementasikan, serta mengevaluasi pembelajaran daring (2020). Guna mewujudkan pembelajaran daring yang berhasil secara proses maupun secara hasil maka sosok yang paling berperan dalam implementasinya ada pada peran pendidik (Herlambang, 2018; Tilaar, 2017). Seorang pendidik pada hakikatnya adalah satu sosok vital dalam proses pendidikan selain orang tua dan lingkungan. Oleh sebab itu, maka tugas dan fungsi guru dalam pembelajaran daring di masa pandemi Covid-19 membuat proses pembelajaran yang bermakna, menyenangkan, serta mampu mengembangkan minat dan bakat siswa. Akan tetapi sebelum guru dapat melakukan tersebut, maka niscaya para pendidik mesti mempunyai keterampilan yang dapat menunjang guna mengaplikasikan pola pembelajaran yang sesuai dengan kondisi lingkungan dan kebutuhan siswa (Jufri et al., 2018; Nugraha, 2018; Suryapermana, 2017).

Berkaitan dengan pembelajaran daring, abad ke-21 yang ditandai perkembangan ilmu pengetahuan dan teknologi telah merubah tatanan 
kehidupan dalam multiaspek, tidak terkecuali pendidikan. Hal tersebut memberi dampak signifikan terhadap praktik pendidikan yang harus terintegrasi dengan teknologi. (Herlambang, 2018). Integrasi teknologi dalam pendidikan, baik praktik integrasi teknologi, persepsi dan hambatan telah dikaji selama lebih dari empat dekade (Lowther et al., 2008). Derasnya arus teknologi, berjalan secara drastis setiap detik waktu. Oleh sebab itu, ide dan cara pandang terhadap teknologi dan integrasi teknologi pun berubah. Jalur integrasi teknologi baru terus dieksplorasi dalam rangka pengembangan untuk perubahan dan kemajuan pendidikan. Istilah teknologi mengacu pada semua jenis aplikasi, termasuk perangkat keras, perangkat lunak, komputer, basis data, Internet dan email (Tubaishat et al., 2016), yaitu konsep ini luas dan digunakan untuk merujuk pada aplikasi perangkat keras dan perangkat lunak yang digunakan untuk menyimpan, membuat, bertukar, dan menggunakan informasi (Nkosi et al., 2011).

Mengintegrasikan teknologi dianggap sebagai salah satu tantangan utama abad ke-21 (Nurjanah, et al 2020; Dinc, 2019; Scherer \& Siddiq, 2015). Guru perlu memahami bahwa penerapan teknologi akan secara efektif membantu pada pengajaran dan hasil pembelajaran yang diharapkan (Cheok et al., 2016; Prestridge \& De Aldama, 2016). Teknologi dapat mendukung motivasi, otonomi, komitmen, komunikasi dan kolaborasi sebagai upaya dalam membangun pembelajaran aktif yang bermakna (Heflin et al., 2017; Mioduser et al., 2008)

Penggunaan teknologi dalam pembelajaran memiliki beberapa manfaat diantaranya ialah pembelajaran menjadi lebih menarik, dapat meningkatkan motivasi siswa dan membekali siswa untuk literat dalam menggunakan teknologi. Dengan demikian, pembelajaran berbasis teknologi merupakan hal yang sangat penting dan perlu dilakukan. (Calderón et al., 2020; Dogan \& Robin, 2008; Langran \& Alibrandi, 2012; J. Lee \& Molebash, 2004; Y. J. Lee, 2019). Teknologi digital merupakan elemen penting dalam pendidikan abad ke-21 (Nurjanah, et al, 2020; Henderson et al., 2017). Pada abad ke-21 ini teknologi digital telah mendapat posisi yang penting dan diharapkan dapat mengoptimalkan pembelajaran siswa di sekolah (Tondeur et al., 2007). Sejumlah penelitian tentang integrasi teknologi digital dalam pembelajaran sudah pernah dilakukan oleh (Balakrishnan, 2014; Cutajar, 2019; Lackovic et al., 2017; Y. J. Lee, 2019; Ng'Ambi, 2013) menganjurkan bahwa pentingnya menggunakan teknologi dalam pembelajaran. Namun penggunaan teknologi dalam pembelajaran harus memerhatikan pedagogi teknologi yang didasarkan pada pembelajaran otentik yang berpusat pada siswa (Casey et al., 2017)

Pemanfaatan dan pengintegrasian teknologi merupakan sebagai salah satu tantangan utama abad ke-21 (Scherer \& Siddiq, 2015)yang dapat memberi implikasi terhadap hasil pembelajaran yang diharapkan (Cheok et al., 2016; Heflin et al., 2017; Prestridge \& De Aldama, 2016), Selain itu, teknologi dapat mendukung kemandirian, komitmen, komunikasi dan kolaborasi sebagai upaya dalam membangun efektivitas pembelajaran aktif dan bermakna (Mioduser et al., 20o8). Oleh sebab itu, hal ini perlu didukung oleh kompetensi guru, khususnya kompetensi pedagogik. Hal ini penting dipahami karena kompetensi pedagogik 
merupakan salah satu hal esensial bagi seorang guru dalam menjalankan peran dan fungsinya.

Salah satu kompetensi yang harus dikuasai oleh guru tersebut yakni kompetensi pedagogik (Destiana \& Utami, 2017). Adapun kompetensi pedagogik merupakan kemampuan seorang pendidik dalam melakukan manajemen, penyusunan strategi, dan perencanaan serta evaluasi pembelajaran terhadap peserta didik. Berpijak pada hal tersebut Tyagita \& Iriani (2018) mengemukakan bahwa kompetensi pedagogik akan berguna dalam keberhasilan siswa dalam proses pembelajaran, karena pendidik yang menguasai kompetensi pedagogik akan dapat dan mampu mengelola pembelajaran dengan terarah dan sesuai target capaian baik itu dilalukan dengan konsep pembelajaran luring maupun daring.

Hal tersebut sejalan dengan Supriyono (2017) yang mengemukakan bahwa semakin tinggi kompetensi pedagogik yang dimiliki seorang pendidik, maka kinerja pendidik dalam melaksanakan kegiatan pembelajaran akan lebih baik guna mencapai tujuan pembelajaran. Namun demikian, Nengsih (2017) menjelaskan bahwa masih terdapat beberapa hal yang dapat menjadi penghambat seorang pendidik dapat menguasai kompetensi pedagogik, di antaranya yakni: 1) Pemahaman terhadap peserta didik; 2) Merancang proses dan evaluasi pembelajaran; 3) Pemahaman guru terhadap kurikulum, serta; 4) Rendahnya kemampuan dalam menggunakan teknologi. Oleh sebab itu, untuk mengantisipasi rendahnya kompetensi pedagogik pendidik dapat dilakukan dengan adanya Uji Kompetensi Guru (UKG) secara berkala guna mengevaluasi kinerja guru demi meningkatkan kualitasnya (Sappaile, 2017). Selain itu, untuk meningkatkan kualitas guru dalam konteks kompetensi pedagogik adalah dengan memperluas ide, gagasan, dan inovasi pendidik dalam melakukan proses pembelajaran (Abidin \& Herlambang 2019; Herlambang, 2018).

Salah satu inovasi yang dapat diterapkan oleh pendidik dalam melakukan pembelajaran transformatif di era sekarang yakni melalu pembelajaran dengan pendekatan multimodal (Al Fajri, 2018). Adapun multimodal pada dasarnya merupakan sebuah pendekatan yang memungkinkan pembelajaran dilakukan dengan berbagai media, metode, dan sumber belajar (Merchant, 2009). Dalam pendekatan multimodal, pendidik dapat melaksanakan pembelajaran dengan sangat fleksibel, pendidik dapat menggunakan media berbasis audio, visual, maupun audio visual (Y. J. Lee, 2019). Untuk metode, pendidik dapat juga memvariasikan berbagai metode ke dalam sebuah pembelajaran. Selain itu, dalam pendekatan multimodal siswa juga diperkenankan untuk memperoleh sumber dari multisumber, baik itu internet, koran, buku, majalah, dan lain sebagainya. Selain itu Marchetti \& Valente (2018) mengemukakan bahwa pendekatan multimodal memungkinkan siswa untuk dapat lebih interaktif dalam proses pembelajaran.

Hasil penelitian sebelumnya menyatakan bahwa pedagogik penting dalam pembelajaran secara daring dan akan dapat membantu dalam meningkatkan efektivitas pembelajaran (Serdyukov, 2015). Kesiapan pendidik dalam merancang pembelajaran secara daring membutuhkan pemahaman dan keterampilan pedagogik (van Rooij \& Zirkle, 2016). Penelitian yang dilakukan 
oleh Mulenga \& Marbán (2020) menjelaskan bahwa pembelajaran secara daring dan bertatap muka memberikan perbedaan yang sangat signifikan dan perbedaan tersebut harus dilihat faktor-faktor yang mempengaruhinya. Hasil lainnya menunjukkan bahwa dalam pembelajaran perlu adanya perencanaan pembelajaran daring yang didasarkan pada suatu kajian yang tepat (Hegeman, 2015).

Berkaitan dengan hal di atas, dalam implementasi pembelajaran matematika secara daring di masa pandemik covid-19, harus ditunjang oleh kompetensi pedagogik guru, agar pembelajaran daring tidak sampai kehilangan esensi pembelajaran dan dapat memberikan dampak yang positif dalam pembelajaran. Sehingga penelitian sebelumnya menjelaskan bahwa pentingnya dalam melihat dimensi-dimensi pedagogik dalam pembelajaran matematika secara daring dan perlu dilakukan kajian dalam mengupayakan suatu perencanaan pembelajaran daring yang efektif. Berdasarkan hal tersebut, menjadi titik tolak peneliti untuk melakukan sebuah riset tentang dimensi-dimensi pedagogik dalam pembelajaran daring.

\section{B. Method}

Penelitian ini menggunakan pendekatan kualitatif dengan metode eksplorasi (Creswell, 2016). Studi eksplorasi yaitu mengeksplorasi temuan-temuan yang ada dalam membantu menjawab pertanyaan penelitian (Merrick, 1999; Stebbins, 2012). Tujuan dari penelitian ini yaitu akan mengeksplorasi bagaimana tantangan dan kesiapan guru dalam pembelajaran matematika daring dilihat dari dimensi pedagogik dan meninjau kemungkinan upaya-upaya yang bisa dilakukan dalam perbaikan pembelajaran matematika secara daring. Subjek penelitian merupakan orangtua/wali siswa dan guru yang melakukan pembelajaran matematika secara daring. Instrumen yang digunakan yaitu kuesioner dan wawancara. Instrumen kuesioner akan melihat fenomena-fenomena proses pembelajaran matematika secara dari sebelumnya. Sementara wawancara dilakukan untuk melihat kepastian harapan orangtua/wali siswa dan upayaupaya yang dilakukan dalam perbaikan proses pembelajaran. Instrumen yang digunakan sudah divalidasi dan menghasilkan nilai validasi sebesar o,803. Hasil validasi tersebut mengindikasikan bahwa instrumen yang digunakan sudah sangat valid (Azwar, 2012). Analisis data menggunakan statistik deskriptif (Larson \& Farber, 2012) dan analisis Bogdan \& Biklen (1982). Analisis ini digunakan untuk melihat fenomena yang ada dilapangkan pada pembelajaran matematika secara daring. fenomena-fenomena tersebut akan tergambarkan dalam bentuk statistik yang nantinya diperjelas dengan kajian analisis secara kualitatif yang lebih mendalam.

\section{Result \& Discussion}

Temuan penelitian menunjukkan bagaimana tantangan pembelajaran matematika secara daring, hal ini menjadi sebuah fenomena baru yang dialami oleh lembaga pendidikan, guru, siswa, dan juga orang tua dalam upaya mewujudkan proses pembelajaran yang bermutu.

\section{Tantangan pembelajaran matematika secara daring}

Berkaca dari realitas di lapangan peneliti menemukan beberapa tantangan dalam implementasi 
pembelajaran matematika secara daring di masa pandemik, adapun hal-hal yang menjadi temuan dalam hal ini terangkum pada tabel berikut:

\section{Tabel 1. Tantangan Pembelajaran Matematika secara Daring}

\begin{tabular}{|c|c|c|}
\hline Temuan & Kategori & Simpulan \\
\hline $\begin{array}{l}\text { Guru perlu pengetahuan teknologi } \\
\text { agar bisa merancang pembelajaran } \\
\text { dengan baik } \\
\text { Harus mengerti penggunaan aplikasi } \\
\text { untuk belajar }\end{array}$ & $\begin{array}{l}\text { Literasi digital } \\
\text { guru }\end{array}$ & \multirow{7}{*}{$\begin{array}{l}\text { Pembelajaran matematika } \\
\text { secara daring } \\
\text { menimbulkan berbagai } \\
\text { masalah yang tidak } \\
\text { terduga. Masalah-masalah } \\
\text { tersebut menjadi salah } \\
\text { satu tantangan utama } \\
\text { dalam menghadapi } \\
\text { pembelajaran matematika } \\
\text { secara daring. adapun } \\
\text { beberapa tantangan yang } \\
\text { perlu dihadapi oleh guru } \\
\text { yaitu peningkatan literasi } \\
\text { digital, pengayaan fasilitas } \\
\text { pembelajaran, } \\
\text { peningkatan karakter } \\
\text { siswa, dan evaluasi } \\
\text { pembelajaran. }\end{array}$} \\
\hline Kurangnya fasilitas untuk belajar & \multirow{2}{*}{\begin{tabular}{|l} 
Fasilitas \\
pembelajaran
\end{tabular}} & \\
\hline $\begin{array}{l}\text { Guru harus pandai memilih aplikasi } \\
\text { dan disesuaikan dengan perangkat } \\
\text { yang dipunya siswa }\end{array}$ & & \\
\hline Semenjak daring anak jadi sulit diatur & \multirow[t]{2}{*}{ Karakter } & \\
\hline Gampang marah karena daring & & \\
\hline Soal-soal yang diberikan membebani & \multirow{2}{*}{$\begin{array}{l}\text { Evaluasi } \\
\text { pembelajaran }\end{array}$} & \\
\hline $\begin{array}{l}\text { Anak kesulitan menjawab soal yang } \\
\text { diberikan }\end{array}$ & & \\
\hline
\end{tabular}

Dari Tabel 1. terlihat bahwa terdapat banyak temuan yang menjadi tantangan dalam pembelajaran matematika secara daring. Hal pertama yang menjadi tantangan terletak pada kemampuan literasi digital guru. Hal ini sejalan dengan pendapat Jufri et al., (2018) dan Sa'pang \& Purbojo (2020) yang mengungkapkan bahwa salah satu upaya yang dapat membantu meningkatkan mutu pendidikan di abad ke-21 adalah adanya kesiapan dan kemampuan dari guru dalam memahami serta mampu mengoperasikan teknologi berbasis digital. Selain itu Herlambang (2018) juga mengungkapkan bahwa syarat utama guru di abad ke-21 dan di era digital adalah mempunyai kemampuan dalam hal beradaptasi dengan gaya serta kultur masyarakat yang sedemikian dapat cepat berubah. Sehingga hal ini menunjukkan bahwa peranan literasi digital memberikan dampak yang sangat besar pada proses pelajaran secara daring serta perlu pembiasaan dalam meningkatkan literasi digital (Hatlevik \& Arnseth, 2012; Hobbs, 2010; Ozdamar-Keskin et al., 2015; Prestridge \& De Aldama, 2016).

Poin kedua dalam tantangan pembelajaran matematika secara daring di masa pandemik adalah masih minimnya fasilitas penunjang pembelajaran (Hidayat \& Prasetya, 2019; Iqbal et al., 2016). Dalam pembelajaran daring peran fasilitas pembelajaran yang mumpuni menjadi salah satu kunci keberhasilan proses pembelajaran, karena jika tanpa fasilitas tersebut maka proses pembelajaran akan menjadi terhambat sehingga kemudian akan juga mengurangi capaian tujuan pembelajaran (Astini, 2020; Herlambang, 2018; Hobbs, 2010; Jufri et al., 2018). Oleh sebab itu, maka guru 
perlu pandai dalam menyesuaikan penggunaan aplikasi yang dapat secara mudah di akses oleh siswa dengan fasilitas yang terbatas .

Pada poin ketiga, temuan yang terdapat pada penelitian adalah karakter dari siswa yang cenderung menjadi mudah marah dan sulit diatur. Hal ini menjadi tantangan bagi guru mengenai bagaimana mereka dapat mendesain pembelajaran matematika daring namun dengan pola dan suasana yang menyenangkan bagi siswa (Gazali, 2016; Nurdyansyah \& Aini, 2017). Hal tersebut sejalan pula dengan pendapat Astini (2020)yang mengungkapkan bahwa di masa pandemi, pembelajaran yang disampaikan oleh guru haruslah memberikan kesan yang positif dan menyenangkan bagi siswa. Berkaitan dengan poin ketiga, pada temuan poin keempat, yakni siswa merasa terbebani dengan evaluasi yang diberikan oleh guru. Padahal di masa pembelajaran daring saat pandemi ini, seharusnya pemberian evaluasi dilakukan melalui cara-cara yang variatif dan menyenangkan agar siswa tetap terus termotivasi untuk belajar (Damanik,
Pada tantangan selanjutnya yaitu evaluasi pembelajaran. Ada beberapa temuan yang menunjukkan bahwa pembelajaran secara daring memberikan tekanan pada siswa. Hal ini sejalan dengan temuan Damanik, Zuhdi, \& Herlina (2020) bahwa dalam pembelajaran daring khususnya evaluasi pembelajaran, siswa merasa tertekan dan terbebani. Hal ini perlu dibenahi oleh guru sehingga siswa tidak merasa terbebani. Guru perlu memperbaikinya dengan menyesuaikan evaluasi pembelajaran sesuai dengan takaran yang tepat agar tidak membebani (Riyanda et al., 2020; Yudiawan, 2020; Yusron et al., 2020)

\section{Kesiapan pembelajaran ditinjau dari dimensi pedagogik}

Kesaiapan pembelajaran daring di masa pandemi menjadi salah satu faktor pendorong ke arah berhasil atau tidaknya pembelajaran daring dilaksanakan. Beberapa hal yang ditemukan dalam kesiapan pembelajaran daring ditinjau dari dimensi pedagogik terangkum dalam gambar di bawah ini:

Zuhdi, \& Herlina, 2020)

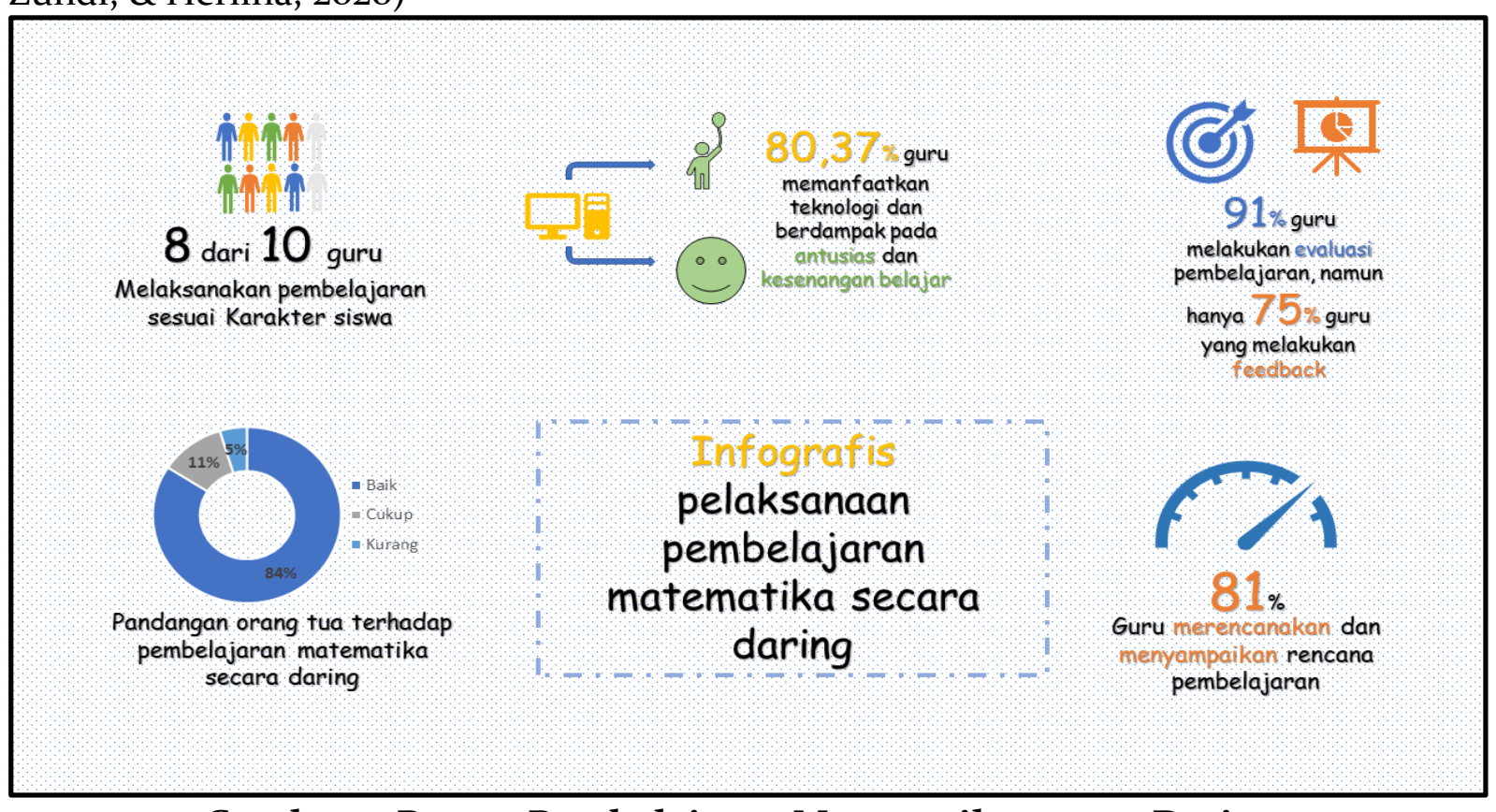

Gambar 1. Proses Pembelajaran Matematika secara Daring 
Dari gambar di atas terlihat bahwa mayoritas guru telah mampu melaksanakan pembelajaran sesuai dengan karakter dari siswa. Hal ini tentu menjadi penting karena dalam melaksanakan pembelajaran maka seorang guru perlu menyesuaikan gaya mengajar dengan karakteristik dari siswa (Gardner, 2013; Sa'pang \& Purbojo, 2020). Dari aspek lainnya, ditemukan juga bahwa mayoritas guru telah mampu merencanakan dan menyampaikan rencana pembelajaran serta memanfaatkan teknologi dalam pembelajaran. Keduanya menjadi bagian penting dalam proses pembelajaran guna mensukseskan pembelajaran matematika daring yang pada intinya membuat siswa paham akan materi ajar dan gembira dalam proses pembelajaran (Dewi, 2020; Syamsuar \& Reflianto, 2019; Winarno et al., 2019).

Selain itu ditemukan pula bahwa sebagian besar guru telah mampu memberikan evaluasi pembelajaran secara daring kepada siswa, meskipun beberapa diantaranya pula masih terdapat yang belum menyertainya dengan pemberian feedback kepada siswa. Berpijak pada hal itu, maka seharusnya guru selain dapat memberikan evaluasi, guru juga harus mampu memberikan timbal balik, bimbingan, dan bantuan terhadap siswa yang mengalami kendala dalam pembelajaran (Nengsih, 2017; Supriyono, 2017). Hal ini dimaksudkan agar setiap siswa dapat terakomodasi setiap kebutuhan dan kekurangannya dalam pembelajaran oleh guru. Namun demikian dalam penelitian ini ditemukan pula data bahwa mayoritas orang tua menyatakan bahwa pembelajaran matematika secara daring sejauh ini telah cukup baik dilakukan oleh sekolah dan guru.

3. Upaya yang dilakukan guru pada pembelajaran matematika daring Melihat bahwa pembelajaran matematika daring dari dimensi pengetahuan masih mengalami beberapa kendala, maka diperlukan upaya-upaya yang mengarah pada peningkatan kualitas pembelajaran matematika daring, adapun beberapa cara yang dapat dilakukan dalam mencapai hal tersebut yang ditemukan pada penelitian ini adalah sebagai berikut:

Tabel 2. Upaya peningkatan kualitas pembelajaran pada dimensi pengetahuan

\begin{tabular}{|c|c|c|}
\hline Temuan & Kategori & Simpulan \\
\hline $\begin{array}{l}\text { Memahami platform yang digunakan } \\
\text { agar maksimal }\end{array}$ & \multirow[t]{2}{*}{$\begin{array}{l}\text { Literasi } \\
\text { Teknologi }\end{array}$} & \multirow{7}{*}{$\begin{array}{l}\text { Dalam melaksanakan } \\
\text { pembelajaran yang lebih } \\
\text { baik perlu adanya upaya- } \\
\text { upaya yang bisa } \\
\text { dilakukan dalam } \\
\text { meningkatkan kualitas } \\
\text { pembelajaran. Upaya } \\
\text { tersebut dapat dimulai } \\
\text { dari peningkatan kualitas } \\
\text { pemahaman guru } \\
\text { tentang literasi teknologi, } \\
\text { perencanaan yang } \\
\text { inovatif/kreatif, dan } \\
\text { pemahaman guru } \\
\text { tentang perkembangan }\end{array}$} \\
\hline $\begin{array}{l}\text { Harus luwes dalam menggunakan } \\
\text { video call dll. }\end{array}$ & & \\
\hline $\begin{array}{l}\text { Harapannya lebih inovatif supaya } \\
\text { anak2 bisa enjoy belajarnya }\end{array}$ & \multirow[t]{2}{*}{$\begin{array}{l}\text { Inovatif/Kreatif } \\
\text { perencanaan }\end{array}$} & \\
\hline $\begin{array}{l}\text { Lebih kreatif dan inovatif dalam } \\
\text { menggunakan media pembelajaran, } \\
\text { tidak hanya share link Youtube saja }\end{array}$ & & \\
\hline $\begin{array}{l}\text { Di kelompokkan antara yg pintar dan } \\
\text { yg kurang dlm belajar }\end{array}$ & \multirow{3}{*}{$\begin{array}{l}\text { Pemahaman } \\
\text { guru akan } \\
\text { perkembangan } \\
\text { belajar }\end{array}$} & \\
\hline $\begin{array}{l}\text { Secara perlahan memahami murid } \\
\text { agar murid mengerti pembelajaran }\end{array}$ & & \\
\hline Harus memahami kemampuan anal & & \\
\hline
\end{tabular}




\begin{tabular}{|l|l|l|}
\hline & & $\begin{array}{l}\text { siswa. Hal-hal tersebut } \\
\text { menjadi sangat pening } \\
\text { dalam meningkatkan } \\
\text { kualitas pembelajaran. }\end{array}$ \\
\hline
\end{tabular}

Dari tabel di atas terlihat bahwa terdapat tiga hal utama yang perlu dicermati oleh guru dalam peningkatan kualitas pembelajaran pada dimensi pengetahuan yakni literasi teknologi, inovasi dan kreasi, serta pemahaman mengenai perkembangan belajar. Ketiga aspek tersebut menjadi hal yang harus dikuasai oleh guru agar peningkatan kualitas pembelajaran matematika pada dimensi pengetahuan dapat diraih (Batubara, 2018; Gazali, 2016). Hal tersebut juga sejalan dengan pendapat Ibda (2018) yang menyatakan bahwa tingkat pemahaman guru yang mendalam tentang tren dan khususnya perkembangan siswanya menjadi tolak ukur dalam meningkatnya kualitas pembelajaran.

Adapun upaya-upaya konkrit yang dapat dilakukan guru dalam meningkatnya kualitas pembelajaran pada dimensi pengetahuan di antaranya adalah melalui penggunaan platform pembelajaran yang interaktif, suasana pembelajaran yang dibuat mengasyikkan, mengelompokkan siswa yang pintar dan yang kurang dalam belajar, serta secara perlahan memahami setiap karakteristik belajar siswa. Berkaitan dengan di atas, upaya peningkatan kualitas pembelajaran juga perlu dilakukan pada dimensi pelaksanaannya, adapun temuan yang didapat adalah sebagai berikut.

Tabel 3. Upaya peningkatan kualitas pembelajaran pada dimensi pelaksanaan

\begin{tabular}{|c|c|c|}
\hline Temuan & Katagori & Simpulan \\
\hline $\begin{array}{l}\text { Lebih interaktif dan berikan } \\
\text { feedback kepada siswa }\end{array}$ & \multirow[t]{2}{*}{ Komunikasi } & \multirow{7}{*}{$\begin{array}{l}\text { Upaya dalam meningkatkan } \\
\text { kualitas pembelajaran dapat } \\
\text { dilakukan dengan melaksanakan } \\
\text { komunikasi yang baik, dengan } \\
\text { siswa, orang tua dan } \\
\text { lingkungan. Kemudian } \\
\text { bimbingan belajar perlu } \\
\text { dilakukan guna meningkatkan } \\
\text { kualitas pembelajaran. Selain } \\
\text { pendekatan/pembelajaran } \\
\text { menggunakan media teknologi } \\
\text { mempunyai peran yang kucup } \\
\text { baik dalam meningkatkan } \\
\text { kualitas pembelajaran dan yang } \\
\text { terakhir kerjasama dengan } \\
\text { orang tua menjadi poin penting } \\
\text { dalam melakukan peningkatan } \\
\text { kualitas pembelajaran. }\end{array}$} \\
\hline $\begin{array}{l}\text { Selalu memberikan penjelasan } \\
\text { yg mudah di pahami dan di } \\
\text { mengerti. }\end{array}$ & & \\
\hline $\begin{array}{l}\text { Siswa tidak bisa belajar } \\
\text { sendiri, wajib harus ada } \\
\text { pendamping }\end{array}$ & \multirow[t]{2}{*}{ Bimbingan } & \\
\hline $\begin{array}{l}\text { Penjelasan \& pemahaman } \\
\text { pembelajaran matematika ke } \\
\text { siswa perlu bimbingan }\end{array}$ & & \\
\hline $\begin{array}{l}\text { Mempunyai trik } \\
\text { menggunakan teknologi }\end{array}$ & $\begin{array}{l}\text { Pendekatan } \\
\text { menggunakan } \\
\text { media teknologi }\end{array}$ & \\
\hline $\begin{array}{l}\text { Perlu. Karena dalam } \\
\text { penyampaian pembelajaran } \\
\text { daring harus bekerja sama } \\
\text { dengan orang tua }\end{array}$ & \multirow[t]{2}{*}{$\begin{array}{l}\text { Kerjasama pada } \\
\text { proses }\end{array}$} & \\
\hline $\begin{array}{l}\text { Iya,, agar orang tua bisa ikut } \\
\text { membantu menerangkan }\end{array}$ & & \\
\hline
\end{tabular}


kepada anak ketika anak

bertanya

Pada tabel di atas dapat diketahui bahwa dalam dimensi pelaksanaan terdapat berbagai upaya yang dapat dilakukan oleh guru dalam meningkatkan kualitas pembelajaran matematika secara daring. Pertama pada aspek komunikasi, guru harus mampu menjelaskan materi secara jelas namun mudah dimengerti oleh siswa agar mereka paham terhadap apa yang disampaikan oleh guru. Kemampuan komunikasi yang baik akan membuat siswa selain cepat paham, juga merasa senang dalam proses pembelajaran (Herlambang, 2018). Kedua adalah bimbingan, pada aspek ini maka guru perlu berupaya dalam mendampingi siswa dalam belajar, oleh karenanya maka dalam pembelajaran daring siswa tidak dapat dilepas begitu saja, namun tetap diarahkan dan dipantau oleh guru agar dapat memahami materi ajar secara utuh (Khofiatun., Akbar, Sa'dun., dan Ramli, 2016; Sappaile, 2017).

Selanjutnya pendekatan teknologi menjadi upaya lain guna meningkatkan kualitas pembelajaran matematika secara daring (Batubara, 2018). Tentu saja dalam proses pembelajaran daring yang sukses maka diperlukan keahlian dan kemahiran menggunakan teknologi oleh para guru (Destiana \& Utami, 2017). Terakhir, dalam meningkatkan kualitas pembelajaran daring, ditemukan data bahwa dalam pembelajaran daring guru perlu bekerjasama dengan orang tua dalam memantau perkembangan siswa (Astini, 2020). Hal ini tentunya agar siswa yang tidak dapat secara penuh dijangkau oleh guru, dapat tetap terbimbing oleh orang tua di rumah. Lebih jauh, kesinambungan bimbingan orang tua dan guru yang harmonis dalam membina siswa akan berdampak baik pula bagi tumbuh kembang siswa (Dewi, 2020; Herlambang, 2018).

\section{Conclusion}

Berdasarkan penelitian dan pembahasan yang dilakukan terhadap pembelajaran matematika secara daring dalam dimensi pedagogik sebagian besar telah dilakukan secara cukup baik oleh guru dan sekolah. Dalam pembelajaran daring terdapat beberapa tantangan yang harus dilalui oleh guru dalam mencapai tujuan pembelajaran yang diharapkan diantaranya adalah kemampuan literasi digital, kesiapan fasilitas, karakteristik siswa, dan evaluasi. Adapun dari segi kesiapan pembelajaran daring telah terlihat cukup baik dengan mayoritas guru yang telah cukup baik dalam merancang dan melaksanakan proses pembelajaran daring sampai tahap evaluasi. Begitu pula respon cukup baik dari orang tua siswa terhadap pembelajaran daring yang telah dilakukan. Ditinjau dari upaya peningkatan kualitas pembelajaran daring dapat dilakukan dari dua dimensi yakni dari dimensi pengetahuan dan dimensi pelaksanaan. Beberapa upaya yang dapat dilakukan dari kedua dimensi tersebut antara lain adalah meningkatkan kemampuan literasi digital, pengoperasian teknologi, daya kreasi dan inovasi dalam pembelajaran, pemahaman tentang karakteristik setiap siswa, dan kerjasama dengan orang tua.

E. Daftar Pustaka

Abidin, Y \& Herlambang, Y, T (2019). Pedagogik Multiliterasi. Bandung: UPI Press

Al Fajri, T. A. (2018). Pentingnya penggunaan pendekatan multimodal dalam pembelajaran. WASKITA: Jurnal Pendidikan Nilai 
Dan Pembangunan Karakter, 2(1), 57-72.

https://doi.org/10.21776/ub.waskita .2018.002.01.5

Astini, N. K. S. (2020). Pemanfaatan teknologi informasi dalam pembelajaran tingkat sekolah dasar pada masa pandemi covid-19. Jurnal Lampuhyang, 11(2), 13-25.

Azwar, S. (2012). Reliabilitas dan Validitas (4th ed.). Pustaka Pelajar.

Balakrishnan, V. (2014). Using social networks to enhance teaching and learning experiences in higher learning institutions. Innovations in Education and Teaching International, 51(6), 595-606. https://doi.org/10.108o/14703297.2 013.863735

Batubara, H. H. (2018). Pengembangan Media Pembelajaran Matematika berbasis Android untuk Siswa SD/MI. Muallimuna: Jurnal Madrasah Ibtidaiyah, 3(1), 12-27. https://doi.org/10.31602/muallimu na.v3i1.952

Bogdan, R., \& Biklen, S. K. (1982). Qualitative Research for Education: An Introduction to Theories and Methods. Allyn \& Bacon Boston, MA.

Calderón, A., Meroño, L., \& MacPhail, A. (2020). A student-centred digital technology approach: The relationship between intrinsic motivation, learning climate and academic achievement of physical education pre-service teachers. European Physical Education Review, 26(1), 241-262. https://doi.org/10.1177/1356336X198 50852

Casey, A., Goodyear, V. A., \& Armour, K. M. (2017). Rethinking the relationship between pedagogy, technology and learning in health and physical education. Sport,
Education and Society, 22(2), 288304.

https://doi.org/10.108o/13573322.20 16.1226792

Cheok, M. L., Wong, S. L., Mohd Ayub, A. F., \& Mahmud, R. (2016). Understanding Teacher Educators' Beliefs and Use of Information and Communication Technologies in Teacher Training Institute. In Envisioning the Future of Online Learning (pp. 11-21). Springer Singapore.

https://doi.org/10.1007/978-981-100954-9_2

Creswell, J. . (2016). Research Design (4th ed.). Pustaka Pelajar.

Cutajar, M. (2019). Teaching using digital technologies: Transmission or participation? Education Sciences, 9(3). https://doi.org/10.3390/educscigo3 0226

Damanik, S., Zuhdi, M., \& Hazizah, H. (2020). Model evaluasi pembelajaran AUD berbasis daring di RA Nurun Namirah Medan Marelan (studi kasus selama masa pandemi covid-19). Jurnal Pendidikan Dan Keislaman, 3(1), 155-172. http://jurnal.stit-alittihadiyahlabura.ac.id/index.php/ alfatih/article/view/84

Damanik, S., Zuhdi, M., \& Herlina, H. (2020). Model Evaluasi Pembelajaran AUD Berbasis Daring di RA Nurun Namirah Medan Marelan (Studi Kasus Selama Masa Pandemi Covid-19). Al-Fatih: Jurnal Pendidikan Dan Keislaman, 3(1), 155-172. http://jurnal.stit-alittihadiyahlabura.ac.id/index.php/ alfatih/article/view/84

Destiana, B., \& Utami, P. (2017). Urgensi Kompetensi Pedagogik Guru Vokasional pada Pembelajaran Abad 21. Elinvo (Electronics, 
Informatics, and Vocational Education), 2(2), 211-222. https://doi.org/10.21831/elinvo.v2i2. 17368

Dewi, W. A. F. (2020). Dampak COVID19 terhadap Implementasi Pembelajaran Daring di Sekolah Dasar. EDUKATIF : JURNAL ILMU PENDIDIKAN, 2(1), 55-61. https://doi.org/10.31004/edukatif.v 2 ii. 89

Dinc, E. (2019). Prospective Teachers' Perceptions of Barriers to Technology Integration in Education. Contemporary Educational Technology, 10(4), 381398.

https://doi.org/10.30935/cet.634187

Dogan, B., \& Robin, B. R. (2008). Implementation of digital storytelling in the classroom by teachers trained in a digital storytelling workshop. Society for Information Technology $\mathcal{E}$ Teacher Education International Conference (SITE), 2(February), 902-907. http://www.coe.uh.edu/lite/

Gardner, H. (2013). Multiple Intelligences Memaksimalkan Potensi dan Kecerdasan Individu dari Masa Kanak-Kanak hingga Dewasa.

Gazali, R. Y. (2016). Pembelajaran matematika yang bermakna. Math Didactic: Jurnal Pendidikan Matematika, 2(3), 181-19o. https://doi.org/10.33654/math.v2i3. 47

Hatlevik, O. E., \& Arnseth, H. C. (2012). ICT, teaching and leadership: How do teachers experience the importance of ICT-Supportive school leaders? Nordic Journal of Digital Literacy, 7(o1), 55-69.

Heflin, H., Shewmaker, J., \& Nguyen, J. (2017). Impact of mobile technology on student attitudes, engagement, and learning. Computers $\mathcal{E}$ Education, 107, 91-99. https://doi.org/10.1016/j.compedu.2 017.01.006

Hegeman, J. S. (2015). Using InstructorGenerated Video Lectures in Online Mathematics Courses Improves Student Learning. Online Learning, 19(3), 70-87. https://eric.ed.gov/?id=EJ1067530

Henderson, M., Selwyn, N., \& Aston, R. (2017). What works and why? Student perceptions of 'useful' digital technology in university teaching and learning. Studies in Higher Education, 42(8), 1567-1579. https://doi.org/10.108o/03075079.2 015.1007946

Herlambang, Y. T. (2018). Pedagogik Telaah Kritis Ilmu Pendidikan Dalam Multiperspektif. Jakarta: Bumi Aksara.

Hidayat, A., \& Prasetya, E. R. (2019). Peran Teknologi dalam analisis prilaku belajar reflektif berbasis sistem android untuk meningkatkan pembelajaran elearning. Jurnal Gammath, 4(2), 7986.

https://doi.org/10.30736/atl.vii1.81

Hobbs, R. (2010). Digital and Media Literacy: A Plan of Action. A White Paper on the Digital and Media Literacy Recommendations of the Knight Commission on the Information Needs of Communities in a Democracy. ERIC.

Ibda, H. (2018). Penguatan Literacy Baru pada Guru Madrasah Ibtidaiyah dalam Menjawab Tantangan Era Revolusi Industri 4.o. Journal of Research and Thought on Islamic Education (JRTIE), 1(1), 1-21. https://doi.org/10.2426o/jrtie.vii1.1 o64

Iqbal, M., Basuno, E., \& Budhi, G. S. (2016). Esensi dan Urgensi Kaji 
Tindak Partisipatif dalam Pemberdayaan Masyarakat Perdesaan Berbasis Sumberdaya Pertanian. Forum Penelitian Agro Ekonomi, 25(2), 73 . https://doi.org/10.21082/fae.v25n2. 2007.73-88

Jufri, A. W., Ramdani, A., Gunawan, G., Bachtiar, I., \& Wildan, W. (2018). Peningkatan Kompetensi Guru IPA Kota Mataram dalam Memfasilitasi Penguasaan Keterampilan Abad Ke 21 Siswa SMP. Jurnal Pengabdian Magister Pendidikan IPA, 1(1). https://doi.org/10.29303/jpmpi.vii1. 207

Khofiatun., Akbar, Sa'dun., dan Ramli, M. (2016). Peran Kompetensi Pedagogik Guru Dalam Pembelajaran Tematik Di Sekolah Dasar. Jurnal Pendidikan, 1(mei), 984-988.

http://journal.um.ac.id/index.php/ jptpp/article/view/6336

Lackovic, N., Kerry, R., Lowe, R., \& Lowe, T. (2017). Being knowledge, power and profession subordinates: Students' perceptions of Twitter for learning. The Internet and Higher Education, 33, 41-48. https://doi.org/10.1016/j.iheduc.201 6.12.002

Langran, E., \& Alibrandi, M. (2012). Middle school social studies teachers integration of technology to meet 21st century challenges. Meridian, 11(2).

Larson, R., \& Farber, B. (2012). Elementary Statistic Picturing The World (Fifth). Pearson College Division.

Lee, J., \& Molebash, P. (2004). Using digital history for positive change in social studies education. Journal of Computing in Teacher Education, 2o(4), 153-157. www.iste.org

Lee, Y. J. (2019). Integrating multimodal technologies with VARK strategies for learning and teaching EFL presentation: An investigation into learners' achievements and perceptions of the learning process. Australian Journal of Applied Linguistics, 2(1), 17-31. https://doi.org/10.29140/ajal.v2n1.11 8

Lowther, D. L., Inan, F. A., Daniel Strahl, J., \& Ross, S. M. (2008). Does technology integration "work" when key barriers are removed? Educational Media International, 45(3), 195-213. https://doi.org/10.108o/o95239808 02284317

Marchetti, E., \& Valente, A. (2018). Interactivity and multimodality in language learning: the untapped potential of audiobooks. Universal Access in the Information Society, 17(2), 257-274. https://doi.org/10.1007/s10209-0170549-5

Merchant, G. (2009). Learning for the future: Emerging technologies and social participation. In Handbook of Research on New Media Literacy at the K-12 Level: Issues and Challenges (Vol. 1, pp. 1-13). https://doi.org/10.4018/978-160566-120-9.choo1

Merrick, E. (1999). An exploration of quality in qualitative research. Using Qualitative Methods in Psychology, 25(23).

Mioduser, D., Nachmias, R., \& ForkoshBaruch, A. (2008). New Literacies for the Knowladge Society. In International Handbook of Information Technology in Primary and Secondary Education (pp. 2342). Springer US. https://doi.org/10.1007/978-0-38773315-9_5

Mulenga, E. M., \& Marbán, J. M. (2020). 
Prospective Teachers' Online Learning Mathematics Activities in The Age of COVID-19: A Cluster Analysis Approach. Eurasia Journal of Mathematics, Science and Technology Education, 16(9). https://doi.org/10.29333/ejmste/83 45

Nengsih, D. H. (2017). Analisis kompetensi pedagogik guru dalam pengelolaan proses di SD Negeri 10 Mandonga. Jurnal Penelitian, 2(7), 1-14.

http://ojs.uho.ac.id/index.php/wak apendikips/article/view/2561

Ng'Ambi, D. (2013). Effective and ineffective uses of emerging technologies: Towards a transformative pedagogical model. British Journal of Educational Technology, 44(4), 652-661. https://doi.org/10.1111/bjet.12053

Nkosi, Z. Z., Asah, F., \& Pillay, P. (2011). Post-basic nursing students' access to and attitudes toward the use of information technology in practice: A descriptive analysis. Journal of Nursing Management, 19(7), 876882. https://doi.org/10.1111/j.13652834.2011.01303. $\mathrm{x}$

Nugraha, M. (2018). Manajemen kelas dalam meningkatkan proses pembelajaran. Tarbawi: Jurnal Keilmuan Manajemen Pendidikan, $4(\mathrm{or})$, 27.

https://doi.org/10.32678/tarbawi.v 4io1.1769

Nurjanah, N, Herlambang, Y, T, Gandana, G \& Hendrawan, B. (2020). Regional Language Education In The Era Of The Industrial Revolution Era 4.0: An Idea About Education In The Techno Pedagogy Perspective. Journal of Physics: Conference Series. Vol 1477. 1-5

Nurdyansyah, N., \& Aini, Q. (2017).
Peran Teknologi Pendidikan Pada Mata Pelajaran Matematika Kelas III di MI Ma'arif Pademonegoro Sukodono. At-Thullab: Jurnal Pendidikan Guru Madrasah Ibtidaiyah, $\quad 1(1), \quad 124$. https://doi.org/10.30736/atl.vii1.81 Ozdamar-Keskin, N., Ozata, F. Z., Banar, K., \& Royle, K. (2015). Examining Digital Literacy Competences and Learning Habits of Open and Distance Learners. Contemporary Educational Technology, 6(1), 74-90. https://doi.org/10.30935/cedtech/6 140

Prestridge, S., \& De Aldama, C. (2016). A Classification Framework for Exploring Technology-Enabled Practice-FrameTEP. Journal of Educational Computing Research, 54(7), 901-921. https://doi.org/10.1177/07356331166 36767

Riyanda, A. R., Herlina, K., \& Wicaksono, B. A. (2020). Evaluasi Implementasi Sistem Pembelajaran Daring Fakultas Keguruan dan Ilmu Pendidikan Universitas Lampung. Jurnal IKRA-ITH Humaniora, 4(1), 66-71. https://journals.upiyai.ac.id/index.php/ikraithhumaniora/article/view/669

Sa'pang, A. W., \& Purbojo, R. (2020). Efikasi diri guru, pemahaman tentang karakter siswa, dan pemahaman tentang keterampilan Abad ke-21 sebagai prediktor gaya mengajar tipe fasilitator. Jurnal Psikologi Ulayat, 2580-1228. https://doi.org/10.24854/jpu1o8

Sappaile, N. (2017). Pengaruh Kompetensi Pedagogik, Kompetensi Profesional, dan Sikap Profesi Guru Tehadap Kinerja Penilaian Guru di Sekolah Dasar. Jurnal Teknologi Pendidikan, 19(1), 
66-81.

http://journal.unj.ac.id/unj/index. $\mathrm{php} / \mathrm{jtp} / \mathrm{article} / \mathrm{view} / 5334$

Scherer, R., \& Siddiq, F. (2015). Revisiting teachers' computer selfefficacy: A differentiated view on gender differences. Computers in Human Behavior, 53, 48-57. https://doi.org/10.1016/j.chb.2015.0 6.038

Serdyukov, P. (2015). Does online education need a special pedagogy? Journal of Computing and Information Technology, 23(1), 6174 .

https://doi.org/10.2498/cit.1002511

Stebbins, R. (2012). Exploratory Research in the Social Sciences. In Exploratory Research in the Social Sciences.

https://doi.org/10.4135/9781412984 249

Supriyono, A. (2017). The Inluence of Pedagogic, Professional Competency, and Work Motivation on Teacher Performance of Elementary School. Jurnal Pendidikan, 18(2), 1-12. http://www.jurnal.ut.ac.id/index.p hp/jp/article/view/269

Suryapermana, N. (2017). Manajemen Perencanaan Pembelajaran. Tarbawi: Jurnal Keilmuan Manajemen Pendidikan, 3(02), 183193.

https://doi.org/10.32678/tarbawi.v3 io2.1788

Syamsuar, \& Reflianto. (2019). Pendidikan dan tantangan pembelajaran berbasis teknologi informasi di era revolusi industri 4.o. In e-Tech: Jurnal Ilmiah Teknologi Pendidikan (Vol. 6, Issue 2).

http://ejournal.unp.ac.id/index.ph p/e-tech/article/view/101343

Tilaar, H. (2017). Pedagogik Teoretis untuk

Indonesia.

https://ebooks.gramedia.com/id/b uku/pedagogik-teoretis-untukindonesia

Tondeur, J., Van Braak, J., \& Valcke, M. (2007). Curricula and the use of ICT in education: Two worlds apart? British Journal of Educational Technology, 38(6), 962-976. https://doi.org/10.1111/j.14678535.2006.00680.x

Tubaishat, A., Aljezawi, M., AlRawajfah, O. M., Habiballah, L., \& Akhu-Zaheya, L. M. (2016). Exploring changes in nursing students' attitudes towards the use of technology: A four-wave longitudinal panel study. Nurse Education Today, 38, 101-106. https://doi.org/10.1016/j.nedt.2015.1 2.006

van Rooij, S. W., \& Zirkle, K. (2016). Balancing pedagogy, student readiness and accessibility: A case study in collaborative online course development. The Internet and Higher Education, 28, 1-7. https://doi.org/10.1016/j.iheduc.201 5.08.001

Winarno, W., Zuhri, M., Mansur, M., Sutomo, I., \& Widhyahrini, K. (2019). Development of Assessment for the Learning of the Humanistic Model to Improve Evaluation of Elementary School Mathematics. International Journal of Instruction, 12(4), 49-64. https://doi.org/10.29333/iji.2019.124 $4 \mathrm{a}$

Yudiawan, A. (2020). BELAJAR BERSAMA COVID 19: Evaluasi Pembelajaran Daring Era Pandemi di Perguruan Tinggi Keagamaan Islam Negeri, Papua Barat. $A L-$ FIKR: Jurnal Pendidikan Islam, 6(1), 10-16.

https://doi.org/10.32489/alfikr.v6iı. 
64

Yusron, E., Retnawati, H., \& Rafi, I. (2020). Bagaimana hasil penyetaraan paket tes USBN pada mata pelajaran matematika dengan teori respons butir? Jurnal Riset Pendidikan Matematika, 7(1), 1-12. https://doi.org/https://doi.org/10.2 1831/jrpm.v7i1.31221 